\title{
Release of vasoactive intestinal polypeptide from the cat small intestine exposed to cholera toxin
}

\author{
J CASSUTO,* J FAHRENKRUG, M JODAL, R TUTTLE, AND O LUNDGREN \\ From the Department of Physiology, University of Göteborg, Sweden, and the Department of Clinical Chemistry, \\ Bispebjerg and Glostrup Hospital, Copenhagen, Denmark
}

SUMMARY During a four hour observation period vasoactive intestinal polypeptide (VIP) is released in increasing amounts from the feline small intestine exposed to cholera toxin. As VIP is known to be located almost exclusively in the intestinal nerves, the present findings strongly suggest that cholera toxin activates the enteric nervous system. The findings of this and other studies performed in this laboratory lead to the proposal that the choleraic secretion is, at least in part, secondary to the activation of intramural nervous reflexes in the gut.

Choleraic secretion is usually believed to be induced via a direct action of the cholera toxin on the intestinal epithelial cells. ${ }^{1}$ However, in recent reports from this laboratory it has been proposed that nervous mechanisms are involved in the production of the fluid loss seen in cholera. 23 This proposal is based on experiments showing, among other things, that the administration of tetrodotoxin, a nerve conduction blocking agent, abolished the choleraic secretion in cats. It has recently been suggested that vasoactive intestinal polypeptide (VIP), a potent intestinal secretagogue, is a neurotransmitter in the gastrointestinal tract. ${ }^{4}$ Futhermore, immunohistochemical investigations have demonstrated VIP containing neurons in the muscle layer, in the nerve plexuses, around blood vessels, and in close proximity to the epithelial cells in the crypts and villi. ${ }^{6}$ It was therefore considered to be of interest to elucidate if VIP was released from intestinal segments exposed to cholera toxin. Such experiments are described below. A preliminary report of this study has been published.7

\section{Methods}

OPERATIVE PROCEDURES

The experiments were performed on cats anaesthetised with chloralose $(50 \mathrm{mg} / \mathrm{kg}$ body weight) after induction with ether. The cats had been deprived of food for 24 hours with free access to water. They exhibited no obvious signs of gastrointestinal disease.

*Address for correspondence: Dr Jean Cassuto, Department of Physiology, Box 33031, S-400 33 Göteborg, Sweden.

Received for publication 7 May 1981
The operative procedures were similar to those described by Jodal et al. ${ }^{8}$ After a tracheotomy the abdomen was opened by a midline incision and a $10-15 \mathrm{~cm}$ long segment from mid-jejunum was isolated with intact vascular supply. The remainder of the small intestine, the colon, the spleen, and the great omentum were extirpated.

In all experiments the splanchnic nerves were cut bilaterally and in seven experiments the distal ends were mounted on ring electrodes. The stimulation characteristics in these experiments were $6 \mathrm{~Hz}, 6 \mathrm{~V}$, $6 \mathrm{~ms}$. The left adrenal gland was denervated and the right one excluded from the circulation by ligatures to minimise changes in the adrenal output of catecholamines while maintaining the necessary release of adrenal steroids. Atropine $(0.5 \mathrm{mg} / \mathrm{kg}$ body weight $)$ was given intravenously.

After heparinisation $(3 \mathrm{mg} / \mathrm{kg}$ body weight intravenously) the femorat artery was cannulated and mean arterial blood pressure was recorded by means of a Statham pressure transducer (P23AE). In order to measure total venous outflow, the superior mesenteric vein draining the intestinal segment and its lymph nodes was cannulated and returned to the external jugular vein via an optical drop recorder, coupled to an ordinate writer recording on a Grass polygraph. The intestinal venous outflow pressure was kept constant at $8-10 \mathrm{mmHg}$ throughout the experiments. Local intra-arterial injections were given by means of a catheter in a small branch of the superior mesenteric artery.

RECORDING OF INTESTINAL NET WATER

TRANSPORT

In most experiments the rate of intestinal net water 
transport was followed continuously with the technique by Jodal et al. ${ }^{8}$ Briefly, the lumen of the isolated intestinal segment was perfused at a constant rate $(1 \mathrm{ml} / \mathrm{min}$ ) with a solution of known composition (see below) in a closed perfusion system with a reservoir large enough to prevent recirculation. Changes in the circulating volume were continuously recorded by a volume transducer coupled to a Grass polygraph and connected to the perfusion system via a T-tube. When no intestinal motility occurred the changes in the perfusion volume reflected net water transport across the intestinal epithelium. In a few experiments choleraic secretion was determined by continuously monitoring the intestinal tissue weight as described by Cassuto et al. ${ }^{3}$

\section{SOLUTION}

The lumen of the intestinal segments was perfused with a modified Krebs-Henseleit solution containing (mmol/l): $\mathrm{NaCl} 122 ; \mathrm{KCl} 4 \cdot 7 ; \mathrm{KH}_{2} \mathrm{PO}_{4} 1 \cdot 2 ; \mathrm{MgCl}_{2} \times 6$ $\mathrm{H}_{2} \mathrm{O} 1 \cdot 2 ; \mathrm{CaCl}_{2} 2 \cdot 5 ; \mathrm{NaHCO}_{3} 25$; mannitol 30. The osmolality of the solution ranged between 305 and 315 $\mathrm{mOsm}_{2} / \mathrm{kg} \mathrm{H}_{2} \mathrm{O}$.

\section{EXPERIMENTAL PROCEDURES}

After the preoperative procedures were completed the animals were allowed to 'rest' for 30-45 minutes after which control measurements of the different parameters studied were made. Two blood samples for VIP determination were collected via a $\mathrm{T}$ tube connected to the venous drop recording unit. The blood was collected in ice-cooled plastic tubes (volume $3 \mathrm{ml}$ ) containing $100 \mu \mathrm{l}(1000 \mathrm{KIE})$ of the protease inhibitor, aprotinin (Trasylol, Bayer AB, Sweden). Concomitantly, the arterial sample was taken via the cannula in the femoral artery. The tubes were kept on ice until centrifugation. One millilitre of plasma was pipetted off and frozen at $-20^{\circ} \mathrm{C}$.

In order to produce a choleraic secretion $300-400 \mathrm{mg}$ per $15 \mathrm{~cm}$ intestine of a crude cholera toxin (freeze dried culture filtrate; NIH lot 001), dissolved in 5-10 ml physiological saline, was introduced into the intestinal lumen. (The toxin was kindly supplied by Dr Jan Holmgren, Department of Medical Microbiology, University of Göteborg). After 30 minutes' exposure, the intestinal lumen was carefully rinsed with $50 \mathrm{ml}$ saline at body temperature. The animals were studied for another four to five hours during which all developed intestinal secretion. Throughout this period arterial blood pressure, intestinal blood flow, and intestinal net fluid transport were continuously recorded. Arterial and venous plasma samples for VIP determination were taken, in the manner described above, $60,120,180$, and 240 minutes after the start of the incubation period with cholera toxin.

In six control experiments the cholera toxin solution was heated to $56^{\circ} \mathrm{C}$ for 45 to 60 minutes, which is con- sidered to inactivate the toxin. These experiments were performed exactly as described above.

In seven experiments 4-5 $\mu \mathrm{g}$ tetrodotoxin was given close intra-arterially during choleraic secretion. Tetrodotoxin was administered while clamping the superior mesenteric artery for two minutes. Upon releasing the arterial occlusion, mesenteric venous blood was collected for about one minute and substituted with dextran to avoid generalised effects of tetrodotoxin on the animal. With this procedure a nerve blocking effect was accomplished as judged by the absence of vasoconstrictor effects upon splanchnic nerve stimulation. Blood samples for VIP analysis were collected before and after giving tetrodotoxin.

\section{LABORATORY ANALYSIS}

The concentration of VIP in plasma was measured radioimmunochemically. Details on accuracy, precision, sensitivity, and specificity have been described previously. 910

CALCULATIONS AND STATISTICAL ANALYSIS The rate of release of VIP from intestine into blood was calculated from the arteriovenous plasma VIP concentration difference and plasma flow.

Statistical analysis was performed using the Wilcoxon matched-pairs signed-ranks test or the sign test. ${ }^{11}$ Differences resulting in $\mathbf{P}$ values less than 0.05 were considered to be significant.

\section{Results}

Figure 1 illustrates six control experiments with inactivated cholera toxin. Blood pressure exhibited a slow continuous decrease throughout the experiment while blood flow stayed fairly constant. Net fluid absorption was recorded in all control experiments and, though it showed a slight tendency to decrease with time, net fluid secretion was never recorded. In five of the six experiments conducted, the release of VIP into the venous blood decreased. This decrease was obvious already in the sample taken one hour after the incubation with the inactivated cholera toxin.

Figure 2 illustrates in a similar way seven experiments with cholera toxin. In the face of a slow, continuous decrease of blood pressure, blood flow increased throughout the experiment. Within 60 to 90 minutes after cholera toxin exposure a net fluid secretion was apparent. VIP release stayed rather constant during the first one to two hours. At three hours the release of VIP from the choleraic segments was on the average almost twice that of controls but the difference was not statistically significant $(0 \cdot 10<P$ $<0.05)$. At four hours VIP release had increased further and reached a value four to five times that of the corresponding value for the control segments. At that 
time a statistically significant difference between the two groups was apparent $(P=0.01)$.

It is apparent from Figs. 1 and 2 that the VIP release during the control period in the two experimental series differed, although it did not reach statistical significance $(P>0 \cdot 10)$. In order to make a comparison between the relative changes in VIP release in the control and choleraic experiments, the VIP release was

\section{MEAN ARTERIAL BLOOD \\ PRESSURE, $\mathrm{mm} \mathrm{Hg}$}
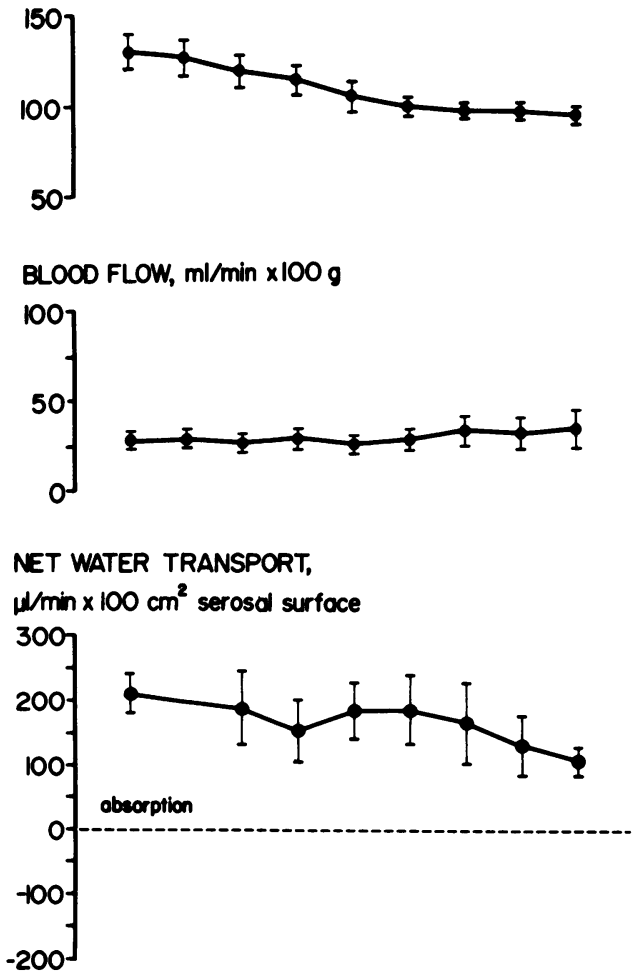

VIP RELEASE, $\mathrm{pmol} / \mathrm{min} \times 100 \mathrm{~g}$

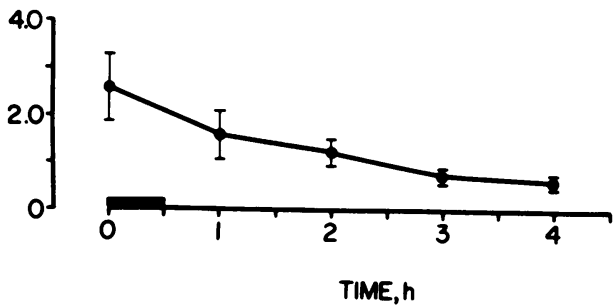

Fig. 1 The effect of heat inactivated cholera toxin on mean arterial blood pressure, intestinal blood flow, intestinal net water transport, and intestinal release of vasoactive intestinal polypeptide (VIP). The intestinal segments were exposed to the inactivated cholera toxin for 30 minutes (signal). Bars denote $\pm S E, n=6$.

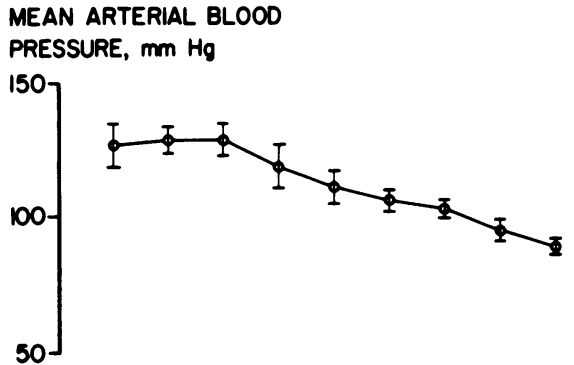

BLOOD FLOW, $\mathrm{ml} / \mathrm{min} \times 100 \mathrm{~g}$

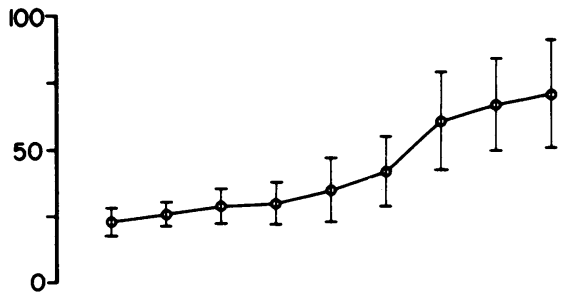

NET WATER TRANSPORT,

$\mu / / \min \times 100 \mathrm{~cm}^{2}$ serosol surfoce

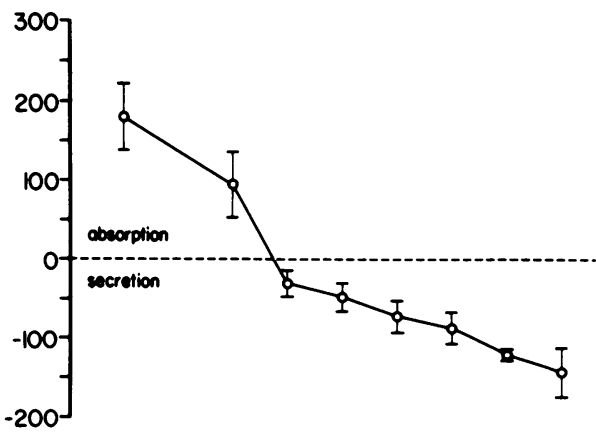

VIP RELEASE, $\mathrm{pmol} / \mathrm{min} \times 100 \mathrm{~g}$

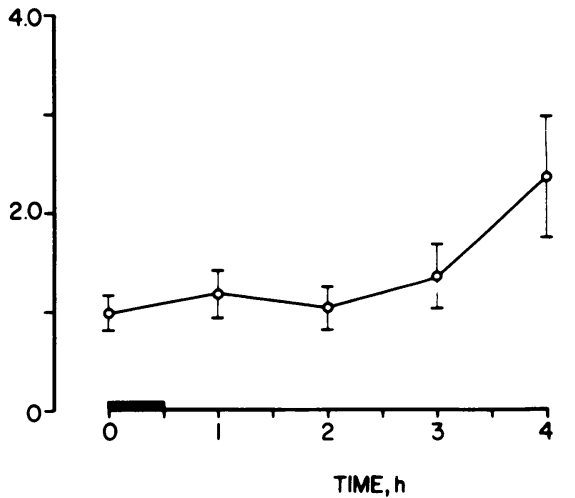

Fig. 2 The effect of cholera toxin on mean arterial blood pressure, intestinal blood flow, intestinal net water transport. and intestinal release of vasoactive intestinal polypeptide $(V I P)$. The cholera toxin was incubated in the intestinal segments for 30 minutes (signal). Bars denote $\pm S E, n=7$. 


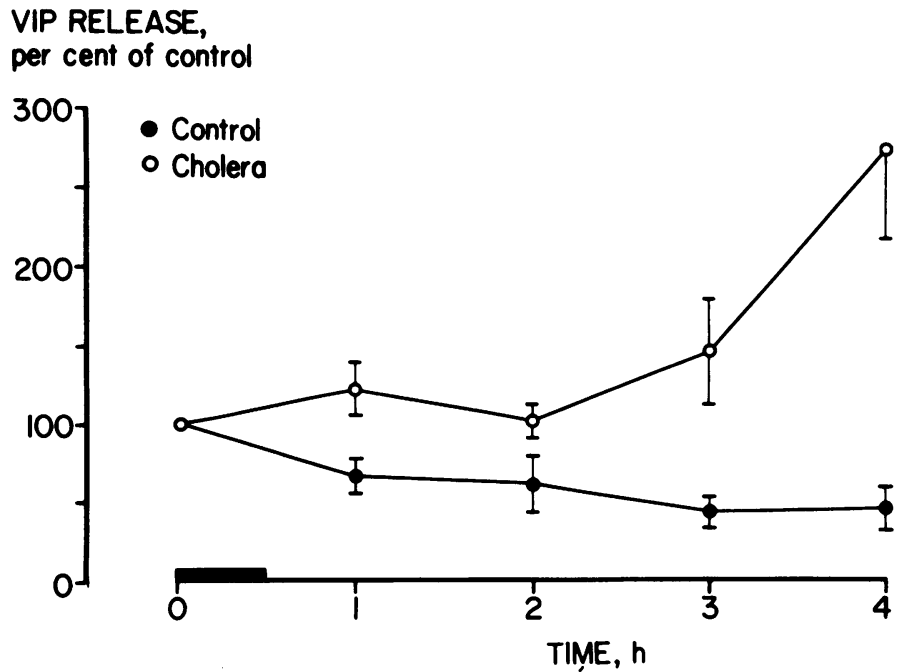

Fig. 3 The relative change of vasoactive intestinal polypeptide (VIP) release from the small intestine after exposing intestinal segments to heat inactivated ('control') and normal ('cholera') cholera toxin. The toxin was exposed to the intestinal mucosa for 30 minutes (signal). Bars denote $\pm S E$.

VIP RELEASE, $\mathrm{pmol} / \mathrm{min} \times 100 \mathrm{~g}$

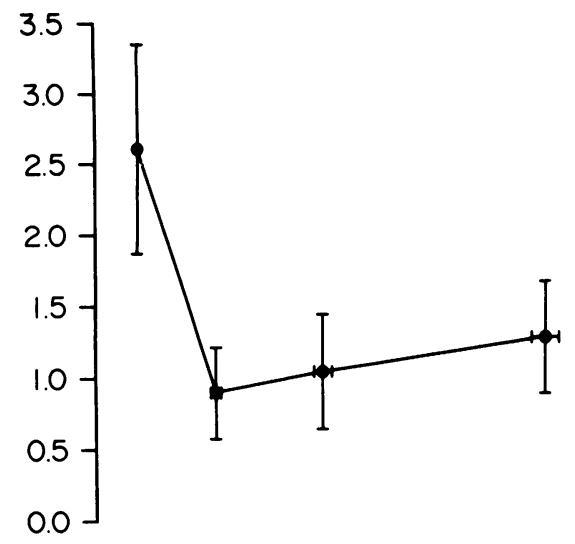

NET FLUID SECRETION, $\mu \mathrm{l} / \mathrm{min} \times 100 \mathrm{~cm}^{2}$ serosal surface

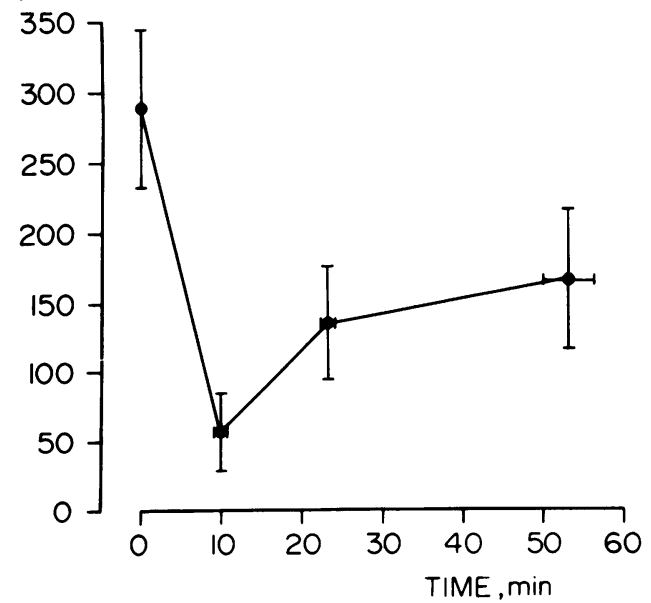

calculated in percentage of control and these results are illustrated in Fig. 3. Making a statistical evaluation of the results presented in this fashion revealed a statistically significant difference that was apparent at the one hour observation $(P=0.02)$.

In seven experiments tetrodotoxin was administered intra-arterially to the choleraic intestine. This resulted in a marked decrease in VIP release (Fig. 4). Simultaneously net water secretion was inhibited as recorded in five experiments. A complete blockade of nerve conduction was demonstrated by the absence of any vasoconstrictor effect upon splanchnic nerve stimulation. With the return of VIP release towards control value, nerve function was restored and an increased net fluid secretion was observed. The correlation coefficient for the relationship between VIP release and net fluid transport varied between 0.84 and 0.96 in the individual experiment.

\section{Discussion}

The present experiments have demonstrated that inducing a fluid secretion in the small intestine of the cat by exposing the mucosa to cholera toxin results in a release of VIP into the intestinal venous effluent. These observations are in agreement with the preliminary findings reported by Bloom et al. 12 that the stool water of choleraic patients contained high concentrations of VIP. The increased VIP release was possibly initiated already during the first hour after incubating the gut

Fig. 4 The effect of tetrodotoxin on intestinal release of vasoactive intestinal polypeptide (VIP) and intestinal net fluid secretion. Tetrodotoxin was administered close intraarterially at time 0 . Bars denote $\pm S E$. 
with the toxin (Fig. 3). Concomitantly, a decrease of net water absorption was observed (Fig. 2). Furthermore, in experiments where tetrodotoxin was given intraarterally, a close correlation was observed between VIP release and rate of secretion (Fig. 4).

The localisation of VIP in the intestintal tissue has been investigated by means of immunohistochemical methods. These have shown that most, if not all, VIP is contained within nervous tissue (see, for example, ref. 13). In the gastrointestinal tract a substantial fraction of these nerves is probably intrinsic-that is, confined to the wall-as extrinsic denervation failed to decrease the amount of VIP in the gastrointestinal tract. 131415 The present study also suggested that VIP was released from intestinal nerves as close intraarterial administration of tetrodotoxin, a nerve conduction blocking agent, inhibited the release. Thus, the present observations are in agreement with the proposals made in an earlier publication from this laboratory that nervous mechanisms are involved in the pathogenesis of choleraic secretion. 23

The distribution of nerves containing VIP in the intestinal wall has been the subject of several recent reports. 6131516 They demonstrate VIP-ergic nerve fibres not only around non-VIP-immunoreactive nerve cells in the intestinal nerve plexa but also around blood vessels and at the epithelial cells in the crypts of Lieberkühn and in the villi. Hence, it seems possible that VIP neurones may participate in the control of intestinal absorption/secretion and/or blood flow. This proposal is supported by the observation that VIP infused intravascularly evokes a vasodilatation and an intestinal secretion. ${ }^{17-19}$ It should be underlined, however, that the present study does not make it possible to determine the exact site of VIP release.

A statistically significant increase of VIP release from choleraic segments was not observed until three to four hours after introducing the toxin into the intestinal lumen, when basing the comparisons on the actual release of VIP. When the relative changes of VIP discharge were compared, a statistically significant difference could already be demonstrated at one hour. The reason for this difference is that the observed control values for VIP release differed in the control and cholera groups. It is therefore difficult to determine if the increase of VIP discharge and the change from net fluid absorption into net fluid secretion exhibited a 'similar time course or not.

The present and a previous report ${ }^{3}$ strongly suggest the involvement of intrinsic nervous reflexes in the pathogenesis of choleraic secretion. It seems possible that one major effect of the cholera toxin is to activate nervous reflex(es), the net effect being a loss of fluid from the intestine. In line with this we presented evidence in previous reports ${ }^{720}$ that cholera toxin triggers the release of serotonin from the entero- chromaffin cells, which, in turn, may activate enteric nerves, among them VIP-ergic neurones. Such nervous mechanism(s) may account for about $60 \%$ of the effect of cholera toxin on intestinal fluid transport. ${ }^{3}$

It is well known that the content of cyclic AMP is augmented in any type of cells when exposed to cholera toxin. It has also been clearly demonstrated that the cyclic AMP concentration in isolated intestinal epithelial cells is markedly increased by even very low concentrations of VIP (about $\left.10^{-9} \mathrm{~mol} / \mathrm{l}\right) .^{21}$ The concentration of the intracellular cyclic nucleotide showed a steady increase during a 15 minute period of VIP incubation. Thus, if the VIP release observed in this study occurred at the intestinal epitheliàl cells, it may in part explain the increase of cyclic AMP seen in cholera.

The skilful technical assistance of Eva Bengtsson, Pia Larsson, Lisbeth Lindgren, Lene Poulsen, Nina Rasmussen, and Anne Sylvest is gratefully acknowledged. The study was supported by grants from the Danish Medical Research Council (J. no. 512-7221), P Carl Petersens Foundation (B 1048, B 1093), Magnus Bergvalls Foundation, the Swedish Medical Research Council (2855), and the Swedish Society for Medical Sciences.

\section{References}

${ }^{1}$ Field M. Intracellular mediators of secretion in the small intestine. In: Binder $\mathrm{HJ}$, ed Mechanisms of intestinal secretion. New York: Alan R Liss, 1979; 83-91.

${ }^{2}$ Cassuto J, Jodal M, Tuttle R, Lundgren $\mathrm{O}$. The effect of lidocaine on the secretion induced by cholera toxin in the cat small intestine. Experientia (Basle) 1979; 35:1467-8.

${ }^{3}$ Cassuto J, Jodal M, Tuttle R, Lundgren O. On the role of intramural nerves in the pathogenesis of cholera toxin induced intestinal secretion. Scand J Gastroenterol 1981; 16:377-84.

${ }^{4}$ Fahrenkrug J, Galbo H, Holst JJ, Schaffalitzky de Muckadell OB. Influence of the autonomic nervous system on the release of vasoactive intestinal polypeptide from the procine gastrointestinal tract. $J$ Physiol (Lond) $1978 ; 280: 405-22$.

5Fahrenkrug J, Haglund U, Jodal M, Lundgren O, Olbe L, Schaffalitzky de Muckadell OB. Nervous release of vasoactive intestinal polypeptide in the gastrointestinal tract of cats: possible physiological implication. J Physiol (Lond) 1978; 284:291-305.

6Schultzberg M, Hökfelt T, Nilsson G, et al. Distribution of peptide- and catecholamine-containing neurons in the gastrointestinal tract of rat and guinea-pig: Immunohistochemical studies with antisera to substance $P$, vasoactive intestinal polypeptide, enkephalins, somatostatin, gastrin/ cholecystokinin, neurotensin and dopamine $\beta$-hydroxylase. Neurosciences 1980; 5:689-744.

${ }^{7}$ Cassuto J, Fahrenkrug J, Jodal M, Tuttle R, Lundgren $\mathrm{O}$. The role of 5-hydroxytryptamine and vasoactive intestinal 
polypeptide in the pathogenesis of choleraic secretion. Acta Physiol Scand 1980; 109:37A.

8Jodal M, Hallbäck DA, Svanvik J, Lundgren O. A method for the continuous study of net water transport in the feline small bowel. Acta Physiol Scand 1975; 95:441-7.

${ }^{9}$ Fahrenkrug J, Schaffalitzky de Muckadell OB. Radioimmunoassay of vasoactive intestinal polypeptide (VIP) in plasma. J Clin Med 1977; 89:1379-88.

10Fahrenkrug J, Schaffalitzky de Muckadell OB. Distribution of vasoactive intestinal polypeptide (VIP) in the procine central nervous system. J Neurochem 1978; $31: 1445-51$.

1 Siegel S. Nonparametric statistics for the behavioral sciences. Tokyo: McGraw Hill Kogakusha. 1956.

12Bloom SR, Nalin DR, Mitchell SJ, Bryant MG. Proceedings 1st Int Symp Gastrointestinal Hormones. California: Asilomar. 1976.

${ }^{13}$ Larsson LI, Fahrenkrug J, Schaffalitzky de Muckadell O, Sundler F, Hakansson R, Rehfeld JF. Localization of vasoactive intestinal polypeptide (VIP) to central and peripheral neurons. Proc Natl Acad Sci USA 1976; 73:3197-200.

14Jessen KR, Polak JM, Van Noorden S, Bloom SR, Burnstock G. Peptide-containing neurones connect the two ganglionated plexuses of the enteric nervous system. Nature 1980; 283:391-3.

${ }^{15}$ Costa M, Furness JB, Buffa R, Said SI. Distribution of enteric nerve cell bodies and axons showing immunoreactivity for vasoactive intestinal polypeptide in the guinea-pig intestine. Neuroscience 1980; 5:587-96.

${ }^{16}$ Fuxe K, Hökfelt T, Said SI, Mutt V. Vasoactive intestinal polypeptide and the nervous system: Immunohistochemical evidence for localization in central and peripheral neurons, particularly intracortical neurons of the cerebral cortex. Neuroscience Letters 1977; 5:241-6.

${ }^{17}$ Kachelhoffer J, Eloy MR, Pousse A, Hohmatter D, Grenier JF. Mesenteric vasomotor effects of vasoactive intestinal polypeptide. Study on perfused isolated canine jejunal loops. Pflügers Arch 1974; 353:37-46.

18Eklund S, Jodal M, Lundgren O, Sjöqvist A. Effects of vasoactive intestinal polypeptide on blood flow, motility and fluid transport in the gastrointestinal tract of the cat. Acta Physiol Scand 1979; 105:461-8.

${ }^{19}$ Krejs GJ, Barkley RM, Read NW, Fordtran JS. Intestinal secretion induced by vasoactive intestinal polypeptide. A comparison with cholera toxin in the canine jejunum in vivo. J Clin Invest 1978; $61: 1337-45$.

${ }^{20}$ Nilsson $\mathrm{O}$, Liedberg $\mathrm{P}$, Ahlman $\mathrm{H}$, et al. Effect of cholera toxin on serotonin content of enterochromaffin cells in the cat small intestine. Acta Physiol Scand 1980; 109:11A.

${ }^{21}$ Amiranoff B, Laburthe M, Rosselin G. Characterization of specific binding sites for vasoactive intestinal peptide in intestinal epithelial cell membranes. Biochim Biophys Acta 1980; 627:215-24. 